\title{
VIAJE POR LOS \\ ORIGINALES DE TOLSTÓI
}

Selma Ancira*

\section{En la calle Prechístenka (de la Purí-} sima), muy cerca de la catedral del Cristo Redentor, en uno de los barrios más antiguos y más bellos de Moscú, se encuentra el Museo Tolstói. Es un edificio de principios del siglo XIX con gruesas columnas blancas en el pórtico, un cuidado jardín y dos alas adyacentes. Una de ellas alberga una biblioteca con 140,000 volúmenes de y sobre Lev Tolstói. Allí, en la sala de lectura, hace apenas unos meses descubrí buena parte de los secretos que guarda la correspondencia del descomunal Lev Nikoláievich.

Cuando tomé la decisión de adentrarme en el mundo de sus cartas intuía que la labor sería faraónica. Durante los años que me dediqué a los diarios su correspondencia fue una constante en mi trabajo. En biografías y ensayos sobre el escritor se citan fragmentos de las cartas, se habla de los corresponsales, se dice que la correspondencia tuvo un papel muy importante en el desarrollo de Tolstói como escritor, y también como pensador y filósofo. Con frecuencia me pregunté por qué hasta ahora no existe en castellano una selección generosa y significativa de ese magnífico epistolario. La respuesta la encontré en Moscú. ¡Son más de diez mil las cartas publicadas hasta este momento!

* Traductora del griego, entre otros, de Giorgos Seferis y del ruso de casi toda la prosa de Marina Tsvietáieva. Hace poco seleccionó y tradujo los Diarios de Tolstói publicados en España por Ediciones del Acantilado y en México por Editorial ERA. 
Ya en la sala de lectura del Museo intento no dejarme intimidar por el número de páginas ni por la complejidad del material y comienzo la lectura con entusiasmo. Los destinatarios son los más diversos: Iván Turguéniev, el zar Alejandro II, el poeta Afanasi Fet, el filósofo Alexandr Herzen, la condesa Sofia Andréievna, el crítico Nikolái Strájov, la encantadora Alexandra Andréievna Tolstaia..., y años más tarde Romain Rolland, Iván Bunin, Rainer Maria Rilke, Máximo Gorki, el zar Nicolás II, Vladímir Chertkov, Bernard Shaw, Gandhi... iQué riqueza! Cuántas ideas, cuántas reflexiones, cuántas anécdotas, sueños, viajes, proyectos, cuántas lecturas, cuánta vida brota de aquellas páginas tan bien anotadas, tan bien ordenadas, tan escrupulosamente reunidas y publicadas. Leo con avidez, tomo notas, intento encontrar también las cartas dirigidas a él, leo los tratados filosóficos y religiosos a los que hace constante referencia en sus letras. En fin, me sumerjo en un universo prodigioso que recrea, paso a paso, la vida del creador de Katiusha Máslova.

El trabajo avanza muy poco a poco. Cada año me depara un sinfín de sorpresas, de situaciones y de ideas que no quedaron registradas en sus diarios. Hacer una selección de esas cartas es, definitivamente, todo un reto.

Estoy en 1857. Tolstói viaja por primera vez al extranjero. Pasará seis meses entre Francia, Suiza y Alemania. En sus cartas habla con arrobo de París, donde se ha encontrado con Turguéniev. Es evidente que se ha dejado seducir por la capital francesa. Sin embargo, a comienzos de abril presencia una ejecución y cambia drásticamente de parecer respecto a la república francesa, de donde sale huyendo al cabo de dos días.

El 21 de julio, desde Zurich, le escribe a Vasili Botkin, un literato hoy olvidado pero entonces bastante conocido. Se disculpa por no haberle respondido antes, le cuenta sus planes de viaje, le refiere sus encuentros con Turguéniev y menciona un incidente recientemente acaecido en Lucerna, que él 'siente la necesidad de expresar en papel'. Ese incidente, el lector de hoy en día lo sabe, se convirtió en el relato Lucerna. Continúo la lectura de aquella carta y de pronto me tropiezo 
con la siguiente frase: "En Lucerna atrapé la [1].- ¡A lo que me ha llevado la continencia! - ¡Me fui con la primera que pasó! Ahora estoy en tratamiento...", etcétera. Me llama poderosamente la atención ese 1 entre corchetes. ¿Qué significa? Es evidente que se trata de una enfermedad venérea, pero ¿cuál? ¿Qué debo poner yo en mi traducción? Busco en las notas a pie de página que tan escrupulosamente acompañan cada una de las cartas. No hay ninguna referencia. Voy al detallado texto que precede cada volumen. No encuentro ningún comentario. Consulto en la edición que R. F. Christian, reconocido especialista y celebrado traductor al inglés, hizo de las cartas y leo: "I've picked up syphilis in Lucerne.” ¿¿Sífilis?! Ignoraba que Tolstói hubiera padecido esa enfermedad. Sorprendida, le pregunto a la bibliotecaria si sabe el significado de ese número 1 encerrado entre corchetes. Sí, sabe que eso indica que en el texto ha sido omitida una palabra, y nada más. Cree, sin embargo, que sabremos de qué palabra se trata si consultamos una edición publicada antes de la Revolución bolchevique. Va por el viejo libro. Abrimos 1857, buscamos julio. Encontramos el pasaje. Los corchetes están en su sitio, pero ahora encierran la siguiente frase: “dos palabras tachadas de puño y letra de Tolstói”. ¿Dos palabras? ¿No era una? ¿Qué palabras serán? Y... ¿cómo supo el editor que fue Tolstói quien las tachó? No, esto no sólo no aclara nada, sino que complica el cuadro.

Comento la solución por la que optó mi colega en su edición londinense y el desconcierto no se hace esperar: “¡En Rusia jamás se ha dicho que Tolstói hubiera padecido sífilis!" Me pregunto por qué. ¿Se deberá al falso pudor que reinaba en el mundo socialista? ¿Habrá sido negligencia del traductor al inglés? ¿Cómo habrán resuelto el problema los franceses que publicaron la selección de Christian, pero traduciendo las cartas directamente del ruso?

Recurro, con mi amasijo de dudas, a la directora de la biblioteca, quien coincide en que allí falta una palabra. Pero, ¿cuál? Habrá que averiguar. Saca de las estanterías distintas ediciones de la correspondencia. Las consultamos una a una. Las versiones se contradicen: una corrobora la falta de una palabra, otra dice que faltan dos, otra confir- 
ma que el mismo Tolstói tachó aquel vocablo y otra más que aquella palabra falta por ilegible...

Recurrimos a la edición de Gallimard. Si el traductor tuvo en las manos los originales rusos no cabe duda de que se topó con el mismo problema que yo, y seguramente habrá recorrido un camino similar al mío para solucionarlo. Estoy pensando en esto cuando leo: "J' ai attrapé la syphilis à Lucerne.” ¿Buscaría Bernadette du Crest de qué se contagió Tolstói o simplemente reprodujo la versión inglesa?

Agotadas todas las posibilidades no queda más que consultar el original de aquella carta, pero los manuscritos se encuentran en 'la habitación de acero' y es viernes por la tarde. Habrá que esperar al lunes.

El lunes por la mañana llegué al Museo y encontré sobre mi mesa de trabajo un grueso volumen con el siguiente título: Lev Nikoláievich Tolstói y la medicina, escrito por Grigori Kulízhnikov, un médico que durante cuarenta años rastreó con ejemplar paciencia a lo largo de los trece volúmenes de diarios y de los treinta y un volúmenes de cartas del escritor cada padecimiento, cada malestar, cada una de las dolencias que el conde Lev Nikoláievich soportó durante sus ochenta y dos años de vida. Abro el libro y encuentro, en estricto orden cronológico, las mil y una afecciones del escritor: tosió, se resfrió, le salió un orzuelo, le dolía un diente, se lastimó un brazo, tenía el hígado inflamado, sufrió un mareo... ¡Es un libro de 640 páginas! Busco, pues, 1857, 21 de julio, con la esperanza de hallar la palabra eludida, pero Kulízhnikov no me ayuda: en esa fecha consigna una 'enfermedad aguda de la uretra'.

En eso estoy cuando me entregan una fotocopia de la carta hecha en la 'habitación de acero'. Ávida recorro el papel con la vista, pero la letra de Tolstói es indescifrable. ¡No consigo leer ni una sola palabra! Miro las líneas y no entiendo qué dicen. Busco la frase y no la encuentro. Afortunadamente acude en mi ayuda Tatiana Nikíforova, que se ha pasado la vida entre los manuscritos del escritor, y con ella a mi lado voy leyendo poco a poco, letra por letra: "En Lucerna atrapé la..." y una ' $\mathrm{t}$ '. ¿T?, miro inquisitiva a mi interlocutora. Ella lo aclara de inmediato. Es la 't' de tríper. Es decir: gonorrea. ¡Pero no sífilis! ¿De dónde 
salió esa enfermedad? ¿Cómo pudo colarse en la traducción inglesa? ¡Y en la francesa! ¿Por qué?

A partir de ese momento cada vez que me encuentro con un sospechoso par de corchetes acudo a la señora Nikíforova y ella me responde con fotocopias hechas en la misteriosa 'habitación de acero'.

Mi curiosidad con respecto a la 'habitación de acero' es cada día más grande. Muy pocos han estado allí, pero todos quisieran haberla visitado. ¿Podré entrar algún día? ¿Conseguiré la autorización? Transcurren las semanas. La ciudad reverdece de un día para otro, ya hay más horas de luz, huele a primavera y, animada por el espíritu que se respira alrededor, me atrevo a preguntar si me sería posible hacer una visita a la 'habitación de acero'. Quisiera consultar la carta que Tolstói envió al zar Alejandro III solicitándole que otorgara el indulto a los asesinos de su padre. La respuesta es sí. Acompañada de la señora Nikíforova podré visitarla y hacer todas las consultas que mi trabajo requiera. Mi alegría no puede ser mayor.

Salimos del Museo y recorremos la calle Prechístenka, una de las más suntuosas y mejor conservadas de Moscú. Mi acompañante me comenta los edificios que vamos viendo. En esa hermosísima casa vivió Isadora Duncan con Serguéi Esenin. Ella daba sus clases de baile en los elegantes salones recubiertos de espejos. Más allá hay un magnífico palacio, ahora sede del Museo Pushkin, famoso aun en el siglo XIX por su exquisito buen gusto. Muy cerca se encuentra la casa de los científicos con su espléndido comedor estilo art-nouveau: uno de los lugares preferidos por los moscovitas para reunirse a comer o a tomar el té. Y así, de palacio en palacio, llegamos hasta el que fue el de Iván Morózov, el más célebre coleccionista ruso de arte europeo.

En 1903 Iván Morózov mandó construir este palacio con una habitación en la que se pudiera poner a salvo su valiosísima colección de pintura impresionista en caso de situaciones extremas. Después de la revolución de octubre, en 1921, el nuevo gobierno otorgó ese espacio al Museo Tolstói para que allí se conservaran los originales del escritor. Es una habitación blindada, con puertas y ventanas de acero y paredes extraordinariamente gruesas. En su interior se conservan todos los 
archivos de Tolstói: más de dos millones y medio de páginas. Los originales en sus múltiples versiones tanto de sus textos literarios, como de los filosóficos, religiosos y pedagógicos. Sus diarios, sus cartas, sus cuadernos de apuntes... ¡Es extraordinario!

Tatiana Nikíforova quiere enseñarme más que la sola carta al zar que yo había pedido ver. Me propone hacer un viaje por los originales. ¡Un viaje por los originales de Tolstói! ¡Qué maravilla! Con un amor que roza la veneración, saca de uno de los cajones del centro de la sala una carpeta de cartón en la que está escrito '1838, redacciones escolares'. La coloca sobre la mesa y la abre. Desdobla el papel que protege el contenido de la carpeta y queda al descubierto un cuaderno sencillísimo. Lo saca, lo pone sobre la mesa y lo abre. Me explica que cuando Tolstói abordó por primera vez el tema de la guerra de 1812 tenía sólo diez años.

Eso nos lleva a hablar de La guerra y la paz. La historia de la creación de esta novela es fascinante. Corren incontables rumores a propósito de las muchas veces que Tolstói rescribió esta obra, de las muchas que su mujer la copió, de las diferentes versiones que se publicaron en vida del autor. Se decía que Tolstói había escrito siete veces la novela de principio a fin. '¿Qué trabajo de titanes!', se comentaba. Son leyendas que siguen vivas y aún hoy los editores se preguntan: ¿qué versión ha de considerarse la definitiva? ¿Existe una versión definitiva? La polémica es ineludible. Tolstói trabajó en La guerra y la paz durante siete años, de 1863 a 1869, aunque la génesis de la novela, según testimonio de Sofia Andréievna, su mujer, se remonta a 1856. Me entusiasma poder ver esos manuscritos, esos borradores, esas diferentes redacciones. Mi guía comienza por el principio: me enseña las hojas de papel que contienen el plan de la novela: las características de los personajes, los esquemas de las escenas, de los distintos episodios, de algunos capítulos ya estructurados. Todo son tachones, flechas, indicaciones, asteriscos, correcciones. La búsqueda es evidente. Luego, de los armarios salen los borradores. Tolstói no está satisfecho con lo que escribe y rescribe, emborrona, garrapatea, corrige. Quince borradores atestiguan esta etapa de su trabajo. ¡Quince! ¡Es fascinante 
estar en el laboratorio de Lev Nikoláievich y participar de sus dudas, de sus reflexiones!... ¿Qué lo habrá impulsado a eliminar esta escena que ya era parte de la novela? ¿Por qué este personaje ahora protagónico más adelante desaparece del texto? ¿Por qué este otro personaje que en un principio despierta la simpatía del autor, tres versiones después le es evidentemente antipático? Quisiera leerlo todo, quisiera estudiarlo todo...

Llegamos por fin a la primera redacción de la novela. Un copista ha puesto el borrador en limpio y ha dejado un margen amplísimo para las correcciones. Pero son tantas las correcciones que hay páginas y páginas añadidas al cuaderno del copista. La nueva versión vuelve a manos del copista. El proceso se repite muchas veces. Muchas. Y en cada nueva versión hay alguna sorpresa: personajes desconocidos, escenas que sólo se parecen a sí mismas, interesantes reflexiones filosóficas que en algún momento el autor consideró banales y dejó fuera de la redacción definitiva... "Pensar en el millón de combinaciones posibles y de entre ellas elegir sólo una es espantosamente difícil", decía Tolstói. Me pierdo, ya no sé qué versión estamos viendo. Lo pregunto. "Es muy difícil saberlo, ya ve lo que es esto", me responden.

Las galeradas también se conservan allí. Entrañables hojas salpicadas aquí y allá de signos tipográficos idénticos a los que utilizamos hoy en día. ¡No han variado un ápice! De signos tipográficos y. . ¡ ¡otra vez de reflexiones e incluso de escenas que se incorporan al texto en esa etapa del trabajo, cuando el libro está a punto de irse a la imprenta! Para desesperación de sus editores, Tolstói llamaba a eso 'mínimas correcciones', y opinaba que sólo favorecerían a la novela. "Eso que tanto les gusta -decía- no sería lo mismo si no lo hubiera yo corregido tantas veces."

El viaje continúa por las distintas versiones de Anna Karénina, las galeradas de Resurrección, los apuntes para Hadzí-Murat, los diarios, las cartas, la carta al zar y, finalmente, la última y muy conmovedora carta que Turguéniev, a sólo dos semanas de su muerte, envió a Tolstói. "Mi querido, mi muy estimado Lev Nikoláievich: Hace mucho tiempo que no le escribo porque he estado y estoy, literalmente, en mi 
lecho de muerte. No podré recuperar la salud, ni siquiera vale la pena que lo piense. En realidad, sólo le escribo para decirle que me siento muy afortunado de haber sido contemporáneo suyo y también para expresarle mi última y más sincera súplica. Amigo mío, ¡vuelva a la literatura! [...] ¡Qué feliz me sentiría si supiera que hará caso a mi súplica! [...]."

¿Qué feliz me siento yo de haber realizado este viaje extraordinario a la génesis de La guerra y la paz, de haber recorrido de la mano del propio Tolstói el largo camino de su novela! ¡De sus novelas! ¡Qué afortunada me siento de poder elevarme hasta la altura necesaria para trasladarlo a mi lengua! ¡De trasladarlo al español como Tsvietáieva trasladaba a Rilke al ruso. De traducirlo entendiendo la traducción como un verdadero acto de amor.

Vuelvo al Museo por la fastuosa Prechístenka y sus palacios. Veo a Isadora Duncan reflejada al infinito en los espejos de sus salones de baile, oigo las procesiones pascuales partiendo de la catedral de Cristo Redentor hacia el monasterio de Novo diévichi, diviso a Tolstói alejarse caminando hacia su casa en Jamóvniki y llego al Museo consciente de haber vivido una experiencia única y agradecida por todos esos tesoros que Moscú no cesa de regalarme. 